\title{
We are good to grow: dynamic integration of cell wall architecture with the machinery of growth
}

\author{
Matheus R. Benatti ${ }^{1,2}$, Bryan W. Penning ${ }^{1,2}$, Nicholas C. Carpita ${ }^{1,2,3}$ and Maureen C. McCann ${ }^{1,2 *}$ \\ Department of Biological Sciences, Purdue University, West Lafayette, IN, USA \\ ${ }^{2}$ Bindley Bioscience Center, Purdue University, West Lafayette, IN, USA \\ ${ }^{3}$ Department of Botany and Plant Pathology, Purdue University, West Lafayette, IN, USA
}

\author{
Edited by: \\ Jose Manuel Estevez, University of \\ Buenos Aires and Consejo Nacional \\ de Investigaciones Científicas y \\ Técnicas, Argentina \\ Reviewed by: \\ Kirk L. Pappan, Metabolon, USA \\ Daniel Cosgrove, The Pennsylvania \\ State University, USA \\ ${ }^{*}$ Correspondence: \\ Maureen C. McCann, Department of \\ Biological Sciences, Purdue \\ University, 915 West State Street \\ West Lafayette, IN, USA. \\ e-mail:mmccann@purdue.edu
}

\begin{abstract}
Despite differences in cell wall composition between the type I cell walls of dicots and most monocots and the type II walls of commelinid monocots, all flowering plants respond to the same classes of growth regulators in the same tissue-specific way and exhibit the same growth physics. Substantial progress has been made in defining gene families and identifying mutants in cell wall-related genes, but our understanding of the biochemical basis of wall extensibility during growth is still rudimentary. In this review, we highlight insights into the physiological control of cell expansion emerging from genetic functional analyses, mostly in Arabidopsis and other dicots, and a few examples of genes of potential orthologous function in grass species. We discuss examples of cell wall architectural features that impact growth independent of composition, and progress in identifying proteins involved in transduction of growth signals and integrating their outputs in the molecular machinery of wall expansion.
\end{abstract}

Keywords: cell wall, cellulose, dicots, extensibility, grasses, growth, pectin, signaling

\section{INTRODUCTION}

Cell expansion integrates "loosening" of existing architecture with synthesis and deposition of new wall components. Golgiassociated syntheses of matrix polysaccharides and their subsequent secretion is coordinated closely with cellulose synthesis at the plasma membrane, which is in turn coordinated with dynamic assembly and rearrangement during wall extension (Cosgrove, 2005). Multiple signal pathways regulate wall biophysics to permit cell expansion by controlling expression of cell wall-related genes. For example, the brassinosteroid-activated transcription factor BES1 binds to promoter elements of most cellulose synthase (CesA) genes (Xie et al., 2011), and NAC and MYB domain-containing transcriptional factors bind to AC-elements of promoters of genes involved in polysaccharide and monolignol syntheses (Zhao and Dixon, 2011).

In elongating cells, cellulose microfibrils are laid down in helical patterns transverse to the long axis of the cell, and are separated and reoriented by tangential forces generated by turgor. Walls of grasses and those of other flowering plants interlace the microfibrils with different matrix constituents (Carpita and Gibeaut, 1993). All dicots and about one-half of all monocots have type I cell walls: a framework of cellulose microfibrils cross-linked primarily by xyloglucans (XyGs) and embedded in a complex matrix of pectic polysaccharides (McCann and Roberts, 1991; Carpita and Gibeaut, 1993); in type II cell walls of the grasses and other commelinid monocots, cellulose microfibrils are cross-linked primarily with glucuronoarabinoxylans (GAXs). Pectins are a small proportion of the matrix polymers, with GAXs providing most of the negatively charged matrix of the type II cell wall (Carpita, 1996). Structural proteins comprise up to $10 \%$ of mass of type I walls, whereas networks of phenylpropanoids are deposited in the type II wall. In contrast to other commelinids, the grasses (Poales) contain a mixed-linkage $(1 \rightarrow 3),(1 \rightarrow 4)-\beta$-D-glucan that is synthesized during cell expansion of grasses and hydrolyzed when growth ceases (Buckeridge et al., 2004).

Cell elongation results in more subtle changes in cell wall composition and architecture than can be revealed by chemical analyses of whole plant organs. Immuno-labeling experiments using a panel of monoclonal antibodies reveals that unique combinations of epitopes are present in highly nuanced patterns along the Arabidopsis root (Pattathil et al., 2010). Infrared spectra of cell walls of maize coleoptiles show that distinct compositional changes occur at 1.5-day intervals (McCann et al., 2007). This dynamic, cellular heterogeneity may be required for wall-modifying activities to alter biophysical properties at precise developmental stages. Tobacco leaves expressing an inducible cucumber $\alpha$-expansin (CsEXP1) promotes leaf growth maximally at the mid-stage of leaf growth (Sloan et al., 2009).

\section{ARCHITECTURAL CHANGES IN CELL WALLS IMPACT ANISOTROPIC GROWTH}

When the structure of the cell wall is severely compromised, the consequence is a strong inhibition of organ elongation. Mutants of primary wall cellulose synthases CesA1, radial swelling1 ( $r s w 1)$, and CesA6, procuste1 (prc1), have reduced anisotropic growth in roots and hypocotyls (Arioli et al., 1998; Fagard et al., 2000). In prc1, cellulose content is only reduced by about one-third, but the mutation results in a fourfold inhibition of growth (Fagard et al., 2000). Anisotropic distributions of microfibril angles deposited during the initial growth phase can account for the growth inhibition if the wall is modeled as a composite material (MacKinnon et al., 2006). Reorientation from transverse to longitudinal in procuste hypocotyls also results in failure to fill gaps in cellulose deposition 
in some regions, possibly contributing to a tendency for cells to rupture (Anderson et al., 2010).

Mutations in genes whose functions are associated with delivery or activation of cellulose synthases, and other plasma membraneresident or membrane-associated proteins, also result in cellulose deficiency and inhibition of elongation growth. CELLULOSE SYNTHASE INTERACTIVE1 (CSI1) is a microtubule-associated protein that bridges CESA complexes and cortical microtubules, mutation of which affects movement of CESA complexes in the plasma membrane (Gu et al., 2010; Li et al., 2012). Site-directed mutations of the phosphorylation sites of CESA1 to mimic alwayson or always-off states provide evidence that CESAs are direct targets of signal pathways impacting elongation (Chen et al., 2010). Mutations in a plasma membrane-associated endo- $(1 \rightarrow 4)-\beta$-Dglucanase, korrigan in Arabidopsis (Nicol et al., 1998) and rice (Zhou et al., 2006) or in COBRA genes, encoding glycosylphosphatidyl inositol-anchored proteins, are cellulose-deficient and compromised in organ elongation in Arabidopsis (Schindelman et al., 2001; Roudier et al., 2005) and rice (Dai et al., 2011).

Loss of cell wall strength to resist turgor pressure is expected with cellulose deficiencies, but similar swelling phenotypes can occur in mutants unaffected in cellulose synthesis. Mutations in two UDP-sugar interconversion pathway genes encoding UDPglucose dehydrogenases cause significant reduction of substitutions to the XyG backbone, arabinan side chains of rhamnogalacturonan (RG) I, and the apiose-containing side chains A and B of RG II (Reboul et al., 2011), with phenotypes of swollen and misshapen roots and cotyledons, and shorter hypocotyls and reproductive organs.

Xyloglucan endo- $\beta$-transglucosylases/hydrolases (XET/XTHs) catalyze the molecular grafting and/or hydrolysis of XyGs in the primary type I cell wall (Rose et al., 2002; Eklof and Brumer, 2010). Galactose-deficient mur3 XyGs bind to cellulose in vivo and in vitro as do wild-type XyGs, but are exceptionally poor substrates for XET - a feature that correlates with cell swelling at the end of growth (Peña et al., 2004). When XyGs of different molecular sizes are fed to pea stems, large polymers of XyG cross-link cellulose microfibrils and slow growth by action of endogenous XET activity, whereas XyG oligosaccharides promote cell elongation (Takeda et al., 2002). RNAi lines with reduced levels of AtXTH18 show decreased primary root growth compared to that of wildtype (Osato et al., 2006), and AtXTH14 and AtXTH26 reduced the extension of heat-inactivated isolated cell walls under constantload extension (Maris et al., 2009). Also, when growing roots were exposed to either recombinant XTH protein, cell elongation is reduced in a concentration-dependent manner and abnormal root hairs are formed, suggesting a role for XET activity in stiffening of the side-walls of root hairs and cells of the elongation zone.

While XET activities may be associated with maintenance of tensile strength by religating XyGs during growth, the actual stress relaxation of the walls required for growth is induced by expansins (Cosgrove, 2005). The expansin superfamily falls into two major groups, called $\alpha$ - and $\beta$-expansin, in both dicots and grasses, but with many more $\beta$-expansins in the grasses (Sampedro and Cosgrove, 2005). The $\alpha$-expansins disrupt hydrogen bonds between polysaccharides (Cosgrove, 2000), including cellulose microfibrils in filter paper (McQueen-Mason and Cosgrove, 1994). The $\beta$-expansin clade also contains maize group-1 pollen allergens, which, unlike $\alpha$-expansins, solubilize homogalacturonans (HGs) and highly arabinose-substituted GAXs from the middle lamellae of maize silks during pollen growth (Tabuchi et al., 2011).

However, modifications to pectins also impact wall mechanical properties in dicots. The mur1 mutant of Arabidopsis is deficient in GDP-mannose dehydratase activity, resulting in the absence of fucose residues in cell wall polymers of the shoot (Bonin et al., 1997). A slight dwarfism and greatly reduced tensile strength of the floral stem suggested that the fucose-containing side-group of XyG might be important for cross-linking during growth. However, O'Neill et al. (2001) showed that the reduced stem growth and tensile strength of the murl mutant is rescued to near wildtype levels by spraying plants with excess boron, thus promoting the dimerization of fucose-deficient side-chains of RG II. Ryden et al. (2003) showed that the tensile strength of murl etiolated hypocotyls was about half that of wild-type but could be similarly rescued. Rescue of the murl phenotype with boron alone shows that RG II dimers are load-bearing and important for cell and organ growth.

Coordinated cell growth in the context of an organ is far more complex than changing biomechanical properties of individual cell walls, and for which the biophysics of cell layers and volumes control organ form (Green, 1996). Osmotic manipulation of wall tension shows regions of "stiffening" interpreted to provide the mechanical determinants for cell patterning (Kierzkowski et al., 2012). The smooth surface of a meristem gives rise to defined undulations by asymmetric cell expansion in a few cells, and these asymmetries pre-stage the pattern of phyllotaxis (Green et al., 1996). A physical undulation induced by asymmetric application of expansin or induction of its expression is sufficient to induce an entire developmental program of organ development, changing phyllotaxis in the apical meristem or leaf shape (Fleming et al., 1997; Pien et al., 2001).

Pectins also appear to be involved in transduction of biophysical signals. HG is synthesized as a heavily methyl-esterified polymer that are de-esterified by pectin methyl esterases (PMEs) to variable extents during cell elongation. Like expansins, modification of methyl esterification of cell wall pectins is linked to organ initiation and control of the normal pattern of phyllotaxis in the apical meristem (Peaucelle et al., 2008, 2011a). Arabidopsis PME5 is regulated by the homeodomain transcription factor BELLRINGER; in the bellringer mutant, PME5 activity is enhanced in the meristem (Peaucelle et al., 2011b). In contrast, PME5 expression is down-regulated in the mutant, which results in reduced internode elongation. These data suggest a dual function for BELLRINGER - a repressor of PME in the meristem dome and an activator of $P M E$ in the elongating stem.

Hydroxyproline-rich glycoproteins (HRGPs) and glycine-rich proteins (GRPs) become cross-linked in walls at the cessation of growth. However, recent work demonstrates that failure to glycosylate these proteins results in defects early in cell growth. An extensin is required for proper cell plate formation during cytokinesis (Cannon et al., 2008). The Arabidopsis prolyl 4-hydroxylase (AtP4H) hydroxylates prolines of glycoproteins, such as extensins, which are $O$-glycosylated with arabinosyl and galactosyl residues by ER- and Golgi-resident glycosyltransferases (Shpak et al., 1999; 
Gille etal., 2009), and then cross-linked upon delivery to the cell wall (Held etal., 2004). Further complexity in structure is revealed by expression of "glycomodules" of synthetic extensins, where variations in the extent of hydroxylation and glycosylation are observed in a cell and tissue-specific manner (Estévez et al., 2006). Blocking O-glycosylation, either chemically by inhibition of $\mathrm{P} 4 \mathrm{H}$ with ethyl-3,4-dihydroxybenzoate or $\alpha, \alpha$-dipyridyl, or genetically by insertional mutagenesis, result in aberrancies in root hair elongation in Arabidopsis (Velasquez et al., 2011).

\section{STRUCTURE/FUNCTION RELATIONSHIPS MAY BE DIFFICULT TO UNCOVER BECAUSE OF FEEDBACK/COMPENSATION MECHANISMS IN MUTANT GENOTYPES}

While severe defects in wall architecture affect anisotropic growth, there is an enormous plasticity in composition and architecture that may compensate, at least in part, for architectural deficiencies. The cellulose synthesis inhibitor dichlorobenzonitrile induces tomato and tobacco culture cells to synthesize a modified type I wall of more highly cross-linked pectin and protein to replace a cellulose-xyloglucan network, whereas barley cells cross-link GAXs with a more extensive polyphenolic network to make a cellulose-free type II wall (Shedletzky et al., 1992). Arabidopsis cells habituated to grow in the cellulose synthesis inhibitor isoxaben alter their cell walls to compensate for the loss of this structural scaffold, and this response is accompanied by strong up-regulation of a glycine-rich cell-wall protein, the CELLULOSE SYNTHASE-LIKE D5, a trichome birefringence-like glycosyltransferase (Bischoff et al., 2010), and a putative glycosyltransferase of unknown function (Manfield et al., 2004). The mur10 mutation in a secondary wall CESA7 results in alterations to pectin side-group composition in primary walls in cells surrounding the vasculature of Arabidopsis (Bosca et al., 2006).

In contrast, primary wall cellulose deficiencies resulting from either mutated CesA3 or CesA1 result in ectopic lignification (Caño-Delgado et al., 2000, 2003). In both Arabidopsis and rice, mutations in other genes associated with cellulose synthesis, such as korrigan and cobra, can result in increased pectin content and/or ectopic lignification (Nicol et al., 1998; Sato et al., 2001; Zhou et al., 2006). In the temperature-sensitive mutant allele of korrigan, altered cell wall1, an increase in pectin content of $62 \%$ is observed when cellulose content is reduced by $60 \%$ at the restrictive temperature (Sato et al., 2001). In rice, mutation in a COBRA-like gene, Brittle Culm-Like4, causes a dwarf phenotype with fewer tillers than the wild-type (Dai et al., 2011), and an increase in levels of pectin: several CesA and CslF genes are up-regulated in the mutant compared to wild-type despite reduced cellulose content, suggesting that interference with cellulose deposition elicits a positive feedback mechanism. Two cellulose-deficient dwarf mutant alleles of kobito1 ( $k o b 1)$, a cell wall-localized protein (Lertpiriyapong and Sung, 2003), have increased pectin content, and an increase in the ectopic deposition of both callose and lignin in dark-grown seedlings (Pagant et al., 2002).

Mutations in a XyG-specific fucosyltransferase (mur2) and galactosyltransferase (mur3) alter or eliminate the $\alpha$-L-Fuc$(1 \rightarrow 2)-\beta$-D-Gal- $(1 \rightarrow 2)$-side group, yet the mutant plants are indistinguishable from wild-type (Vanzin et al., 2002; Madson et al., 2003). These mutants compensate for these mutations by enhancing activity of a second galactosyl transferase that adds galactose to the middle xylosyl residue (Peña et al., 2004). Although acid-growth and wall extensibility is reduced, expansins still induce extension growth in the XyG-less $x x t 1 / x x t 2$ mutant, even though they are missing the primary target of their activity (Park and Cosgrove, 2012a). While the shoots and floral stem are indistinguishable from wild-type in the mur3 mutant, tensile strength is reduced in etiolated hypocotyls (Ryden et al., 2003; Peña et al., 2004). The reduced tensile strength was traced to a near absence of galactosyl side-groups on hypocotyl XyG (Peña et al., 2004). Cell growth is similar to wild-type, but the mur3 hypocotyls present an abnormal swelling and bulging along with an increased diameter of both epidermal and underlying cortical cells.

We have depicted cross-bridging of cellulose microfibrils with XyGs and GAXs as the principal load-bearing interaction in our cell wall models (McCann and Roberts, 1991; Carpita and Gibeaut, 1993). However, double mutations eliminating function of two GT34 xylosyltransferases, XXT1 and XXT2, produce plants with no detectable XyG (Cavalier et al., 2008). Plants grow more slowly, are slightly dwarfed, and form short root hairs with bulging bases, but are otherwise surprisingly healthy. The reduction in XyG content slightly reduces stiffness and tensile strength of $x x+2$ and $x x t 1 x x+2$ mutant hypocotyls but does not significantly impact extensibility or organ growth. A third xylosyltransferase mutant, $x x t 5$, has a phenotype similar to those observed in $x x+1 x x+2$ double mutants, and reduced XyG content and xylosylation of the glucan backbone (Zabotina et al., 2008). Extensibility is enhanced several-fold in the $x x t 1 / x x+2$ mutant by treatment of tissues with endoxylanase, polygalacturonase, and other treatments that disrupt matrix polysaccharides other than XyGs, indicating that GAX and HG may functionally replace XyGs (Park and Cosgrove, 2012a). These authors conclude that the inherently high extensibility of the mutant over wild-type indicates a reinforcing role for XyGs as well as being the optimal extensibility determinant for which GAX and HG cannot completely substitute. Taken together, these observations reveal a curious paradox loss of galactosylation of XyG impacts wall tensile strength in organ failure tests, but complete loss of XyG does not. Park and Cosgrove (2012b) also showed that creep can be induced in wild-type, but not in $x x t 1 / x x t 2$ mutant plants, by enzymes active against both cellulose and XyG; a cocktail of XyG-specific and cellulose-specific enzyme activities is not effective. These results suggest that the load-bearing connection between microfibrils and $\mathrm{XyGs}$ is in a relatively inaccessible region of interaction rather than the extended regions of XyG that span between microfibrils (Park and Cosgrove, 2012b).

\section{MEDIATORS OF SIGNAL TRANSDUCTION PATHWAYS AND CELL WALL STATUS HAVE BEEN IDENTIFIED}

The Catharanthus roseus $(\mathrm{Cr})$ receptor-like kinase (RLK1) family contains 17 Arabidopsis members, of which four, FERONIA (FER), THESEUS1 (THE1), HERCULES1 (HERK1), and HERK2, are implicated in regulation of cell wall deposition and extensibility during growth (Hématy and Höfte, 2008; Steinwand and Kieber, 2010). The the1 mutant was identified as a suppressor of the hypocotyl elongation defect observed in the CESA-defective procuste (Hématy et al., 2007). No visible change in growth or 
development is seen in the 1 alone, but combining the 1 mutation with herk 1 or herk 2 results in decreases in petiole length and shoot growth (Guo etal., 2009a,b). The the1:herk1 double mutant produces a severe dwarf phenotype in the loss-of-function BRASSINOSTEROID RECEPTOR1 (bri1) mutant but partially suppresses the excessive cell elongation phenotype of the gainof-function mutant of the transcription factor involved in brassinosteroid response1, bes1-D (Guo et al., 2009b). Mutations in two other Arabidopsis leucine-rich repeat (LRR)-RLKs, FEI1 and FEI2, cause swollen-root phenotypes (Xu et al., 2008).

Matrix polymers other than cellulose are also involved in signal pathways. Extracellular domains of WALL-ASSOCIATED KINASES (WAKs) directly bind to pectin (Seifert and Blaukopf, 2010; Kohorn and Kohorn, 2012). Mutation of WAK2 or expression of antisense WAK2 or WAK4 to reduce levels of WAK proteins results in reduction in cell elongation (Lally et al., 2001; Wagner and Kohorn, 2001; Kohorn et al., 2006). Expression of genes associated with cell wall biogenesis and pathogen response is WAK2-dependent, suggesting a role in relaying pectin-based signals from the cell wall (Kohorn et al., 2009). Arabinogalactan proteins (AGPs) are highly glycosylated extracellular proteins anchored to the plasma membrane without kinase activities. Exogenous AGP induces somatic embryogenesis in carrot cells (van Hengel etal., 2001), and apical cell elongation in moss depends on a functional AGP (Lee et al., 2005). The Arabidopsis fasciclin-like arabinogalactan1 (fla1) mutant reduces shoot formation in callus regeneration (Johnson et al., 2011), and mutation of an AtAGP19 results in reduction of hypocotyl elongation, but,

\section{REFERENCES}

Anderson, C. T., Carroll, A., Akhmetova, L., and Somerville, C. (2010). Real-time imaging of cellulose reorientation during cell wall expansion in Arabidopsis roots. Plant Physiol. 152, 787-796.

Arioli, T., Peng, L., Betzner, A. S., Burn, J., Wittke, W., Herth, W., Camilleri, C., Höfte, H., Plazinski, J., Birch, R., Cork, A., Glover, J., Redmond, J., and Williamson, R. E. (1998). Molecular analysis of cellulose biosynthesis in Arabidopsis. Science 279, 717-720.

Bischoff, V., Nita, S., Neumetzler, L., Schindelasch, D., Urbain, A., Eshed, R., Persson, S., Delmer, D., and Scheible, W. R. (2010). TRICHOME BIREFRINGENCE and its homolog At5g01360 encode plant-specific DUF231 proteins required for cellulose biosynthesis in Arabidopsis. Plant Physiol. 153, 590-602.

Bonin, C. P., Potter, I., Vanzin, G. F., and Reiter, W. D. (1997). The MUR1 gene of Arabidopsis thaliana encodes an isoform of GDP-D-mannose-4,6dehydratase, catalyzing the first step in the de novo synthesis of GDP-Lfucose. Proc. Natl. Acad. Sci. U.S.A 94, 2085-2090.
Bosca, S., Barton, C. J., Taylor, N. G., Ryden, P., Neumetzler, L., Pauly, M., Roberts, K., and Seifert, G. J. (2006). Interactions between MUR10/CesA7-dependent secondary cellulose biosynthesis and primary cell wall structure. Plant Physiol. 142, 1353-1363.

Buckeridge, M. S., Rayon, C., Urbanowicz, B., Tine, M. A. S., and Carpita, N. C. (2004). Mixed linkage $(1 \rightarrow 3),(1 \rightarrow 4)-\beta$-D-glucans of grasses. Cereal Chem. 81, 115-127.

Cannon, M. C., Terneus, K., Hall, Q. Tan, L., Wang, Y., Wegenhart, B. L., Chen, L., Lamport, D. T., Chen, Y., and Kieliszewski, M. J. (2008). Self-assembly of the plant cell wall requires an extensin scaffold. Proc. Natl. Acad. Sci. U.S.A. 105, 22262231.

Caño-Delgado, A. I., Metzlaff, K. and Bevan, M. W. (2000). The elil mutation reveals a link between cell expansion and secondary cell wall formation in Arabidopsis thaliana. Development 127, 3395-3405.

Caño-Delgado, A., Penfield, S., Smith, C., Catley, M., and Bevan, M. (2003). Reduced cellulose synthesis invokes lignification and defense responses in Arabidopsis thaliana. Plant J. 34, 351-362.

unlike mutations in structural elements, the reduced growth does not result from changes in numbers of cells, cell width, numbers of layers or hypocotyl diameter (Yang et al., 2007).

\section{PROSPECTS}

Despite differences in the structural components of plant cell walls of dicots and grasses, the architectural principles of their construction are similar, giving rise to biophysical properties that underpin common mechanisms of growth. Perturbations to wall architecture, by altering cellulose synthesis and orientation, cross-linking glycan substitution or methyl esterification of the pectin matrix, reveal sensing mechanisms that result in feedback to other biosynthetic pathways. While some candidate components of the sensing mechanisms are receptor kinases or arabinogalactan proteins, a major challenge will be untangling the direct responses of cells to signal transduction mechanisms from the many indirect effects of a life-long deficiency in mutant genotypes. Establishing systems for inducible timing of wall perturbations, introduced by interference with wall synthesis or signal pathways, is a promising approach to unravel the direct integration of growth signals, wall architecture, and biophysical mechanisms of growth.

\section{ACKNOWLEDGMENTS}

This review was completed through support of the Center for Direct Catalytic Conversion of Biomass to Biofuels, an Energy Frontier Research Center funded by the U.S. Department of Energy, Office of Science, Office of Basic Energy Sciences (award no. DE-SC0000997).

Carpita, N. C. (1996). Structure and biogenesis of the cell walls of grasses. Annu. Rev. Plant Physiol. Plant Mol. Biol. 47, 445-476.

Carpita, N. C., and Gibeaut, D. M. (1993). Structural models of primary cell walls in flowering plants: consistency of molecular structure with the physical properties of the walls during growth. Plant J. 3, $1-30$.

Cavalier, D. M., Lerouxel, O., Neumetzler, L., Yamauchi, K., Reinecke, A., Freshour, G., Zabotina, O. A., Hahn, M. G., Burgert, I., Pauly, M., Raikhel, N. V., and Keegstra, K. (2008). Disrupting two Arabidopsis thaliana xylosyltransferase genes results in plants deficient in xyloglucan, a major primary cell wall component. Plant Cell 20, 1519-1537.

Chen, S., Ehrhardt, D. W., and Somerville, C. R. (2010). Mutations of cellulose synthase (CESA1) phosphorylation sites modulate anisotropic cell expansion and bidirectional mobility of cellulose synthase. Proc. Natl. Acad. Sci. U.S.A. $107,17188-17193$.

Cosgrove, D. J. (2000). Loosening of plant cell walls by expansins. Nature 407, 321-326.
Cosgrove, D. J. (2005). Growth of the plant cell wall. Nature Rev. Mol. Cell Biol. 6, 850-861.

Dai, X., You, C., Chen, G., Li, X., Zhang, Q., and Wu, C. (2011). OsBC1L4 encodes a COBRA-like protein that affects cellulose synthesis in rice. Plant Mol. Biol. 75, 333-345.

Eklof, J. M., and Brumer, H. (2010). The XTH gene family: an update on enzyme structure, function, and phylogeny in xyloglucan remodeling. Plant Physiol. 153, 456-466.

Estévez, J. M., Kieliszewski, M. J., Khitrov, N., and Somerville, C. (2006). Characterization of synthetic hydroxyproline-rich proteoglycans with arabinogalactan protein and extensin motifs in Arabidopsis. Plant Physiol. 142, 458-470.

Fagard, M., Desnos, T., Desprez, T., Goubet, F., Refregier, G., Mouille, G., McCann, M., Rayon, C., Vernhettes, S., and Höfte, H. (2000). PROCUSTE1 encodes a cellulose synthase required for normal cell elongation specifically in roots and dark-grown hypocotyls of Arabidopsis. Plant Cell 12, 2409-2423.

Fleming, A. J., McQueen-Mason, S., Mandel, T., and Kuhlemeier, C. (1997). Induction of leaf primordia 
by the cell wall protein expansin. Science 276, 1415-1418.

Gille, S., Haensel, U., Ziemann, M., and Pauly, M. (2009). Identification of plant cell wall mutants by means of a forward chemical genetic approach using hydrolases. Proc. Natl. Acad. Sci. U.S.A. 106, 14699-14704.

Green, P. B. (1996). Expression of form and pattern in plants - A role for biophysical fields. Sem. Cell Dev. Biol. 7, 903-911.

Green, P. B., Steele, C. S., and Rennich, S. C. (1996). Phyllotactic patterns: a biophysical mechanism for their origin. Ann. Bot. 77, 515-527.

Gu, Y., Kaplinsky, N., Bringmann, M., Cobb, A., Carroll, A., Sampathkumar, A., Baskin, T. I., Persson, S., and Somerville, C. R. (2010). Identification of a cellulose synthase-associated protein required for cellulose biosynthesis. Proc. Natl. Acad. Sci. U.S.A. 107, 12866-12871.

Guo, H., Li, L., Ye, H., Yu, X., Algreen, A., and Yin, Y. (2009a). Three related receptor-like kinases are required for optimal cell elongation in Arabidopsis thaliana. Proc. Natl. Acad. Sci. U.S.A. 106, 7648-7653.

Guo, H., Ye, H., Li, L., and Yin, Y. (2009b). A family of receptor-like kinases are regulated by BES1 and involved in plant growth in Arabidopsis thaliana. Plant Signal. Behav. 4, 784-786.

Held, M. A., Tan, L., Kamyab, A., Hare, M., Shpak, E., and Kieliszewski, M. J. (2004). Di-isodityrosine is the intermolecular cross-link of isodityrosinerich extensin analogs cross-linked in vitro. J. Biol. Chem. 279, 55474 55482 .

Hématy, K., and Höfte, H. (2008). Novel receptor kinases involved in growth regulation. Curr. Opin. Plant Biol. 11, 321-328.

Hématy, K., Sado, P. E., Van Tuinen, A., Rochange, S., Desnos, T., Balzergue, S., Pelletier, S., Renou, J. P., and Höfte, H. (2007). A receptorlike kinase mediates the response of Arabidopsis cells to the inhibition of cellulose synthesis. Curr. Biol. 17, 922-931.

Johnson, K. L., Kibble, N. A. J., Bacic, A., and Schultz, C. J. (2011). A fasciclinlike arabinogalactan-protein (FLA) mutant of Arabidopsis thaliana, fla1, shows defects in shoot regeneration. PLOS ONE 6, e25154. doi: 10.1371/journal.pone.0025154

Kierzkowski, D., Nakayama, N., Routier-Kierzkowski, A.-L., Weber, A., Bayer, E., Schorderet, M., Reinhardt, D., Kuhlemeier, C., and Smith, R. C. (2012). Elastic domains regulate growth and organogenesis in the plant shoot apical meristem. Science 335, 1096-1099.

Kohorn, B. D., and Kohorn, S L. (2012). The cell wall-associated kinases, WAKS, as pectin receptors. Front. Plant Sci. 3:88. doi: 10.3389/fpls.2012.00088

Kohorn, B. D., Johansen, S., Shishido, A., Todorova, T., Martinez, R., Defeo, E., and Obregon, P. (2009). Pectin activation of MAP kinase and gene expression is WAK2 dependent. Plant J. 60, 974-982.

Kohorn, B. D., Kobayashi, M., Johansen, S., Riese, J., Huang, L. F., Koch, K., Fu, S., Dotson, A., and Byers, N. (2006). An Arabidopsis cell wall-associated kinase required for invertase activity and cell growth. Plant J. 46, 307-316.

Lally, D., Ingmire, P., Tong, H. Y., and He, Z. H. (2001). Antisense expression of a cell wall-associated protein kinase, WAK4, inhibits cell elongation and alters morphology. Plant Cell 13, 1317-1331.

Lee, K. J. D., Sakata, Y., Mau, S.-L., Pettolino, F., Bacic, A., Quatrano, R. S., Knight, C. D., and Knox, J. P. (2005). Arabinogalactan proteins are required for apical cell extension in the moss Physcomitrella patens. Plant Cell 17, 3051-3065.

Lertpiriyapong, K., and Sung, Z. R. (2003). The elongation defectivel mutant of Arabidopsis is impaired in the gene encoding a serine-rich secreted protein. Plant Mol. Biol. 53 581-595.

Li, S., Lei, L., Somerville, C. R., and Gu, Y. (2012). Cellulose synthase interactive protein 1 (CSI1) links microtubules and cellulose synthase complexes. Proc. Natl. Acad. Sci. U.S.A. 109, 185-190.

MacKinnon, I. M., Sturcova, A., Sugimoto-Shirasu, K., His, I., McCann, M. C., and Jarvis, M. C. (2006). Cell-wall structure and anisotropy in procuste, a cellulose synthase mutant of Arabidopsis thaliana. Planta 224, 438-448.

Madson, M., Dunand, C., Li, X., Verma, R., Vanzin, G. F., Caplan, J., Shoue, D. A., Carpita, N. C., and Reiter, W. D. (2003). The MUR3 gene of Arabidopsis encodes a xyloglucan galactosyltransferase that is evolutionarily related to animal exostosins. Plant Cell 15, 1662-1670.

Manfield, I. W., Orfila, C., McCartney, L., Harholt, J., Bernal, A. J., Scheller, H. V., Gilmartin, P. M., Mikkelsen, J. D., Knox, J. P., and Willats, W. G. T. (2004). Novel cell wall architecture of isoxaben-habituated Arabidopsis suspension-cultured cells: global transcript profiling and cellular analysis. Plant J. 40, 260-275.

Maris, A., Suslov, D., Fry, S. C. Verbelen, J. P., and Vissenberg, K. (2009). Enzymic characterization of two recombinant xyloglucan endotransglucosylase/hydrolase (XTH) proteins of Arabidopsis and their effect on root growth and cell wall extension. J. Exp. Bot. 60, 39593972.

McCann, M. C., Defernez, M., Urbanowicz, B. R., Tewari, J. C., Langewisch, T., Olek, A., Wells, B., Wilson, R. H., and Carpita, N. C. (2007). Neural network analyses of infrared spectra for classifying cell wall architectures. Plant Physiol. 143, 1314-1326.

McCann, M. C., and Roberts, K. (1991). "Architecture of the primary cell wall," in The Cytoskeletal Basis of Plant Growth and Form, ed. C. W. Lloyd. (London: Academic Press), 109-129.

McQueen-Mason, S., and Cosgrove, D. J. (1994). Disruption of hydrogen bonding between plant cell wall polymers by proteins that induce wall extension. Proc. Natl. Acad. Sci. U.S.A. 91, 6574-6578.

Nicol, F., His, I., Jauneau, A., Vernhettes, S., Canut, H., and Höfte, H. (1998). A plasma membrane-bound putative endo- $1,4-\beta$-D-glucanase is required for normal wall assembly and cell elongation in Arabidopsis. EMBO J. 17, 5563-5576.

O’Neill, M. A., Eberhard, S., Albersheim, P., and Darvill, A. G. (2001). Requirement of borate cross-linking of cell wall rhamnogalacturonan II for Arabidopsis growth. Science 294, 846-849.

Osato, Y., Yokoyama, R., and Nishitani, K. (2006). A principal role for AtXTH18 in Arabidopsis thaliana root growth: a functional analysi using RNAi plants. J. Plant Res. 119, 153-162.

Pagant, S., Bichet, A., Sugimoto, K., Lerouxel, O., Desprez, T., McCann, M., Lerouge, P., Vernhettes, S., and Höfte, H. (2002). KOBITO1 encodes a novel plasma membrane protein necessary for normal synthesis of cellulose during cell expansion in Arabidopsis. Plant Cell 14, 2001-2013.

Park, Y. B., and Cosgrove, D. J. (2012a). Changes in cell wall biomechanical properties in the xyloglucandeficient $x x t 1 / x x t 2$ mutant of Arabidopsis. Plant Physiol. 158, 465-475.

Park, Y. B., and Cosgrove, D. J. (2012b). A revised architecture of primary cell walls based on biomechanical changes induced by substrate-specific endoglucanases. Plant Physiol. 158, 1933-1943.

Pattathil, S., Avci, U., Baldwin, D., Swennes, A. G., McGill, J. A., Popper, Z., Bootten, T., Albert, A., Davis, R. H., Chennareddy, C., Dong, R., O'Shea, B., Rossi, R., Leoff, C., Freshour, G., Narra, R., O’Neil, M., York, W. S., and Hahn, M. G. (2010). A comprehensive toolkit of plant cell wall glycan-directed monoclonal antibodies. Plant Physiol. 153, 514-525.

Peaucelle, A., Louvet, R., Johansen, J. N., Hoefte, H., Laufs, P., Pelloux, J., and Mouille, G. (2008). Arabidopsis phyllotaxis is controlled by the methyl-esterification status of cellwall pectins. Curr. Biol. 18, 19431948.

Peaucelle, A., Louvet, R., Johansen, J. N., Salsac, F., Morin, H., Fournet, F., Belcram, K., Gillet, F., Höfte, H., Laufs, P., Mouille, G., and Pelloux, J. (2011a). The transcription factor BELLRINGER modulates phyllotaxis by regulating the expression of a pectin methylesterase in Arabidopsis. Development 138, 4733-4741.

Peaucelle, A., Braybrook, S. A., Le Guillou, L., Bron, E., Kuhlemeier, C., and Höfte, H. (2011b). Pectin-induced changes in cell wall mechanics underlie organ initiation in Arabidopsis. Curr. Biol. 21, 1720-1726.

Peña, M. J., Ryden, P., Madson, M., Smith, A. C., and Carpita, N. C. (2004). The galactose residues of xyloglucan are essential to maintain mechanical strength of the primary cell walls in Arabidopsis during growth. Plant Physiol. 134, 443-451.

Pien, S., Wyrzykowska, J., McQueenMason, S., Smart, C., and Fleming, A. (2001). Local expression of expansin induces the entire process of leaf development and modifies leaf shape. Proc. Natl. Acad. Sci. U.S.A. 98, 11812-11817.

Reboul, R., Geserick, C., Pabst, M., Frey, B., Wittmann, D., LuetzMeindl, U., Leonard, R., and Tenhaken, R. (2011). Down-regulation of UDP-glucuronic acid biosynthesis leads to swollen plant cell walls and severe developmental defects associated with changes in pectic polysaccharides. J. Biol. Chem. 286, 3998239992.

Rose, J. K. C., Braam, J., Fry, S. C., and Nishitani, K. (2002). The XTH family of enzymes involved in xyloglucan endotransglucosylation and endohydrolysis: current perspectives and a new unifying nomenclature. Plant Cell Physiol. 43, 1421-1435.

Roudier, F., Fernandez, A. G., Fujita, M., Himmelspach, R., Borner, G. 
H., Schindelman, G., Song, S., Baskin, T. I., Dupree, P., Wasteneys, G. O., and Benfey, P. N. (2005) COBRA, an Arabidopsis extracellular glycosyl-phosphatidyl inositolanchored protein, specifically controls highly anisotropic expansion through its involvement in cellulose microfibril orientation. Plant Cell 17, 1749-1763.

Ryden, P., Sugimoto-Shirasu, K., Smith, A. C., Findlay, K., Reiter, W. D. and McCann, M. C. (2003). Tensile properties of Arabidopsis cell walls depend on both a xyloglucan cross-linked microfibrillar network and rhamnogalacturonan II-borate complexes. Plant Physiol. 132, 1033 1040.

Sampedro, J., and Cosgrove, D. J. (2005). The expansin superfamily. Genome Biol. 6, 242-250.

Sato, S., Kato, T., Kakegawa, K., Ishii, T., Liu, Y. G., Awano, T., Takabe, K., Nishiyama, Y., Kuga, S., Sato, S., Nakamura, Y., Tabata, S., and Shibata, D. (2001). Role of the putative membrane-bound endo$1,4-\beta$-glucanase KORRIGAN in cell elongation and cellulose synthesis in Arabidopsis thaliana. Plant Cell Physiol. 42, 251-263.

Schindelman, G., Morikami, A., Jung, J., Baskin, T. I., Carpita, N. C., Derbyshire, P., McCann, M. C., and Benfey, P. N. (2001). COBRA encodes a putative GPI-anchored protein, which is polarly localized and necessary for oriented cell expansion in Arabidopsis. Genes Dev. 15, 11151127.

Seifert, G. J., and Blaukopf, C. (2010). Irritable walls: the plant extracellular matrix and signaling. Plant Physiol. 153, 467-478.

Seifert, G. J., and Blaukopf, C. (2010). Irritable walls: the plant extracellular matrix and signaling. Plant Physiol. 153, 467-478.

Shedletzky, E., Shmuel, M., Trainin, T. Kalman, S., and Delmer, D. (1992) Cell-wall structure in cells adapted to growth on the cellulose-synthesis inhibitor 2,6-dichlorobenzonitrile A comparison between two dicotyledonous plants and a gramineous monocot. Plant Physiol. 100, 120 130.

Shpak, E., Leykam, J. F., and Kieliszewski, M. J. (1999). Synthetic genes for glycoprotein design and the elucidation of hydroxyproline- $\mathrm{O}$ glycosylation codes. Proc. Natl. Acad. Sci. U.S.A. 96, 14736-14741.

Sloan, J., Backhaus, A., Malinowski, R., McQueen-Mason, S., and Fleming, A. J. (2009). Phased control of expansin activity during leaf development identifies a sensitivity window for expansin-mediated induction of leaf growth. Plant Physiol. 151, 1844 1854.

Steinwand, B. J., and Kieber, J. J. (2010). The role of receptor-like kinases in regulating cell wall function. Plant Physiol. 153, 479-484.

Tabuchi, A., Li, L. C., and Cosgrove, D. J. (2011). Matrix solubilization and cell wall weakening by $\beta$-expansin (group-1 allergen) from maize pollen. Plant J. 68, 546-559.

Takeda, T., Furuta, Y., Awano, T., Mizuno, K., Mitsuishi, Y., and Hayashi, T. (2002). Suppression and acceleration of cell elongation by integration of xyloglucans in pea stem segments. Proc. Natl. Acad. Sci. U.S.A. 99, 9055-9060.

van Hengel, A. J., Tadesse, Z. Immerzeel, P., Schols, H., van Kammen, A., and de Vries, S. C. (2001). Nacetylglucosamine and glucosaminecontaining arabinogalactan proteins control somatic embryogenesis. Plant Physiol. 125, 1880-1890.

Vanzin, G. F., Madson, M., Carpita, N. C., Raikhel, N. V., Keegstra, K., and Reiter, W. D. (2002). The mur2 mutant of Arabidopsis thaliana lacks fucosylated xyloglucan because of a lesion in fucosyltransferase AtFUT1. Proc. Natl. Acad. Sci. U.S.A. 99, 3340-3345.

Velasquez, S. M., Ricardi, M. M., Dorosz, J. G., Fernandez, P. V., Nadra A. D., Pol-Fachin, L., Egelund, J., Gille, S., Harholt, J., Ciancia, M., Verli, H., Pauly, M., Bacic, A., Olsen, C. E., Ulvskov, P., Petersen, B. L., Somerville, C., Iusem, N. D., and Estevez, J. M. (2011). O-Glycosylated cell wall proteins are essential in roo hair growth. Science 332, 1401-1403.

Wagner, T. A., and Kohorn, B. D. (2001). Wall-associated kinases are expressed throughout plant development and are required for cell expansion. Plant Cell 13, 303-318.

Xie, L., Yang, C., and Wang, X. (2011). Brassinosteroids can regulate cellulose biosynthesis by controlling the expression of CESA genes in Arabidopsis. J. Exp. Bot. 62, 4495-4506.

$\mathrm{Xu}$, S. L., Rahman, A., Baskin, T. I., and Kieber, J. J. (2008). Two leucinerich repeat receptor kinases mediate signaling, linking cell wall biosynthesis and ACC synthase in Arabidopsis. Plant Cell 20, 3065-3079.

Yang, J., Sardar, H. S., McGovern, K. R., Zhang, Y. Z., and Showalter, A. M. (2007). A lysine-rich arabinogalactan protein in Arabidopsis is essential for plant growth and development, including cell division and expansion. Plant J. 49, 629-640.

Zabotina, O. A., van de Ven, W. T. G., Freshour, G., Drakakaki, G., Cavalier, D., Mouille, G., Hahn, M. G., Keegstra, K., and
Raikhel, N. V. (2008). Arabidopsis XXT5 gene encodes a putative $\alpha-1,6-$ xylosyltransferase that is involved in xyloglucan biosynthesis. Plant J. 56, 101-115.

Zhao, Q., and Dixon, R. A. (2011). Transcriptional networks for lignin biosynthesis: more complex than we thought? Trends Plant Sci. 16, 227-233.

Zhou, H. L., He, S. J., Cao, Y. R., Chen, T. Du, B. X., Chu, C. C., Zhang, J. S., and Chen, S. Y. (2006). OsGLU1, a putative membrane-bound endo-1,4- $\beta$ D-glucanase from rice, affects plant internode elongation. Plant Mol. Biol. 60, 137-151.

Conflict of Interest Statement: The authors declare that the research was conducted in the absence of any commercial or financial relationships that could be construed as a potential conflict of interest.

Received: 11 May 2012; accepted: 01 August 2012; published online: 22 August 2012.

Citation: Benatti MR, Penning BW, Carpita NC and McCann MC (2012) We are good to grow: dynamic integration of cell wall architecture with the machinery of growth. Front. Plant Sci. 3:187. doi: $10.3389 / f p l s .2012 .00187$

This article was submitted to Frontiers in Plant Physiology, a specialty of Frontiers in Plant Science.

Copyright (C) 2012 Benatti, Penning, Carpita and McCann. This is an openaccess article distributed under the terms of the Creative Commons Attribution License, which permits use, distribution and reproduction in other forums, provided the original authors and source are credited and subject to any copyright notices concerning any third-party graphics etc. 